\title{
IN MEMORIAM \\ MALCOLM MACDONALD: EDITOR AND FRIEND
}

Malcolm MacDonald was an inspiration and a beacon of light in the world of musicological writing, one of the best authors and editors in his field. To me, he was also one of the most supportive and warmest of colleagues. Though we did not meet face-to-face often (I recall one of the first occasions being a party in honour of his predecessor David Drew), our letters, email correspondence and phone conversations over nearly 30 years (since my first TEMPO contribution in 1986) remain in my memory among my most valued and enriching musical encounters. Our last exchange, just a few months ago, relating to the penultimate issue he edited, was lively and gave no inkling of the extent of his illness: it attested to his remarkable courage and strength of character. Whilst saddened by his untimely loss, I feel privileged to have known him, and to have the chance to contribute to TEMPO under his sage editorship. From the very start, I benefited from his guiding approach to both style and content; his nurturing hand stressed the virtues of clarity and logical argument and the importance of pursuing one's interests. Indeed, he believed that if a critic was sympathetic to a composer or style, the response would be all the more fruitful and creative.

Malcolm was an author in the deep sense of 'authority'. His books, articles, reviews and especially programme notes (for instance, those wonderfully exciting essays for the BBC Proms year by year) are informed and informative, serious and often witty, exploring the human condition and character with common sense and treating complex analytical and aesthetic issues with clarity - qualities any writer, myself included, might strive to emulate. His seminal books on Schoenberg, Brahms and Varèse, and the championing of less mainstream composers like Havergal Brian and Ronald Stevenson, show him to be strikingly pluralistic and non-partisan. For instance: on the Shostakovich debate, I recall one BBC broadcast when he reminded one that, after all, Shostakovich's works were still just 'notes on paper', a caution, perhaps, against over-interpretation. Over the years of his editorship, TEMPO's scope reflected a wide range of international cross-currents that both reflected and shaped the rich discourse about new music, exploring the cutting edge and the coexistence of diverse viewpoints.

As an editor and as a person, Malcolm was kind, generous and patient. I am grateful to have had opportunities to chat from time to time about his own projects, articles, books and compositions, his unceasing activity showing how he was never satisfied to rest on laurels. I had hoped his retirement would bring more occasions to meet. Yet suddenly, Malcolm's kind, wise, often witty voice on the phone is no longer to be heard. 
Malcolm has left an enduring legacy in his writing; he was phenomenally prolific and communicative in the best traditions of musicology and journalism. It is difficult to conceive of a musical world without his human and humane presence. Personally, I shall always remember him as a warm and nurturing mentor. His oeuvre, perhaps some of it still unpublished, will continue to inspire audiences, music lovers and scholars alike for generations to come.

Malcolm Miller 